Article

\title{
Effect of Tocilizumab in Hospitalized Patients with Severe COVID-19 Pneumonia: A Case-Control Cohort Study
}

\author{
Benjamin Rossi ${ }^{1, *,+}$, Lee S. Nguyen ${ }^{2,3,+} \mathbb{D}$, Philippe Zimmermann ${ }^{4}\left(\mathbb{D}\right.$, Faiza Boucenna ${ }^{1}$, \\ Louis Dubret ${ }^{4}$, Louise Baucher ${ }^{1}$, Helene Guillot ${ }^{1}$, Marie-Anne Bouldouyre ${ }^{1}$, Yves Allenbach ${ }^{5}$, \\ Joe-Elie Salem ${ }^{3} \mathbb{D}^{\mathrm{D}}$, Paul Barsoum ${ }^{6}$, Arezki Oufella ${ }^{4}$ and Helene Gros ${ }^{1}$ \\ 1 Department of Internal Medicine, Robert Ballanger Hospital, 93600 Aulnay-Sous-Bois, France; \\ faiza.bou@hotmail.fr (F.B.); louise.baucher@hotmail.fr (L.B.); helene.guillot@ght-gpne.fr (H.G.); \\ marie-anne.bouldouyre@ght-gpne.fr (M.-A.B.); helene.gros@ght-gpne.fr (H.G.) \\ 2 Research \& Innovation of CMC Ambroise Paré, 92200 Neuilly-Sur-Seine, France; nguyen.lee@icloud.com \\ 3 INSERM, Clinical Investigations Center Paris-Est, CIC-1901, Sorbonne Université, AP.HP. Pitié-Salpétrière, \\ 75013 Paris, France; joeelie.salem@gmail.com \\ 4 Department of Pharmacy, Robert Ballanger Hospital, 93600 Aulnay-Sous-Bois, France; \\ philippe.zimmermann6@gmail.com (P.Z.); louis.dubret@ght-gpne.fr (L.D.); arezki.oufella@ght-gpne.fr (A.O.) \\ 5 Department of Internal Medicine and Clinical Immunology, Sorbonne Université, AP.HP. Pitié-Salpétrière, \\ 75013 Paris, France; yves.allenbach@aphp.fr \\ 6 Department of Cardiology, Robert Ballanger Hospital, 93600 Aulnay-Sous-Bois, France; \\ paul.barsoum@ght-gpne.fr \\ * Correspondence: benjamin.rossi@ght-gpne.fr; Tel.: +33-149367021 \\ $\dagger$ These authors equally contributed to the manuscript.
}

Received: 17 September 2020; Accepted: 14 October 2020; Published: 17 October 2020

check for updates

\begin{abstract}
Tocilizumab, an anti-interleukin-6 receptor, administrated during the right timeframe may be beneficial against coronavirus-disease-2019 (COVID-19) pneumonia. All patients admitted for severe COVID-19 pneumonia $\left(\mathrm{SpO}_{2} \leq 96 \%\right.$ despite $\mathrm{O}_{2}$-support $\geq 6 \mathrm{~L} / \mathrm{min}$ ) without invasive mechanical ventilation were included in a retrospective cohort study in a primary care hospital. The treatment effect of a single-dose, $400 \mathrm{mg}$, of tocilizumab was assessed by comparing those who received tocilizumab to those who did not. Selection bias was mitigated using three statistical methods. Primary outcome measure was a composite of mortality and ventilation at day 28. A total of 246 patients were included (106 were treated with tocilizumab). Overall, $105(42.7 \%)$ patients presented the primary outcome, with 71 (28.9\%) deaths during the 28-day follow-up. Propensity-score-matched 84 pairs of comparable patients. In the matched cohort $(n=168)$, tocilizumab was associated with fewer primary outcomes than the control group (hazard ratio $(\mathrm{HR})=0.49(95 \%$ confidence interval $(95 \% \mathrm{CI})=0.3-0.81), p$-value $=0.005)$. These results were similar in the overall cohort $(\mathrm{n}=246)$, with Cox multivariable analysis yielding a protective association between tocilizumab and primary outcome (adjusted HR $=0.26(95 \% \mathrm{CI}=0.135-0.51, p=0.0001)$, confirmed by inverse probability score weighting (IPSW) analysis $(p<0.0001)$. Analyses on mortality only, with 28 days of follow-up, yielded similar results. In this study, tocilizumab $400 \mathrm{mg}$ in a single-dose was associated with improved survival without mechanical ventilation in patients with severe COVID-19.
\end{abstract}

Keywords: anti-interleukin-6; COVID-19; SARS CoV2; severe pneumonia; cytokine release syndrome

\section{Introduction}

The pandemic of the coronavirus disease (COVID-19) started in late 2019. It quickly spread worldwide, notably in Europe [1]. 
It is responsible for severe pneumonia, resulting in a high rate of transfers to intensive care units (ICU) and in-patient mortality of $5 \%$ to $32 \%$ [2,3]. Severity has been related to an exaggerate immune response, the cytokine release syndrome (CRS), mediated by pro inflammatory cytokines, including interleukinIL-6, IL-12 and tumor necrosis factor $\alpha$, leading to various organ dysfunction including the lungs, brain and heart [3]. Previously, tocilizumab, an antibody targeting IL-6 receptors proved efficient against CRS [4]. Opposing CRS may decrease further inflammatory pulmonary lesions, i.e., respiratory deterioration requiring mechanical ventilation, transfers to ICU and death $[5,6]$.

While waiting for the results of ongoing trials studying the effects of tocilizumab on COVID-19 pneumonia, starting on 23 March 2020, we administrated off-label tocilizumab to patients with severe COVID-19 pneumonia as a compassionate use.

In the present report, we assessed the effect of tocilizumab on mortality and mechanical ventilation in a cohort of patients hospitalized for severe COVID-19 pneumonia. To mitigate selection bias, we performed a triple analysis, including propensity-score matching, Cox multivariable and inverse probability score weighting analyses, to compare patients who received tocilizumab, to those who did not.

\section{Results}

In total, 246 patients were included, with 106 patients treated by tocilizumab and compared to 140 control patients (flow-chart is presented in Supplementary Materials). Overall, 105 (42.7\%) patients presented the primary outcome, with 71 (28.9\%) deaths during the 28 days of follow-up. Baseline characteristics and comparisons are presented in Table 1.

Table 1. Baseline characteristics, at admission and at inclusion.

\begin{tabular}{|c|c|c|c|c|c|c|}
\hline & $\begin{array}{l}\text { Control } \\
\text { Group } \\
(n=140)\end{array}$ & $\begin{array}{c}\text { Tocilizumab } \\
\text { Group } \\
(n=106)\end{array}$ & $p$-Value & $\begin{array}{l}\text { Matched } \\
\text { Control } \\
(n=84)\end{array}$ & $\begin{array}{c}\text { Matched } \\
\text { Tocilizumab } \\
\text { Group }(n=84)\end{array}$ & $p$-Value \\
\hline $\begin{array}{c}\text { Age, mean } \pm \text { Standard deviation } \\
(\mathrm{SD}) \text {, years }\end{array}$ & $70.1 \pm 16.5$ & $64.3 \pm 13.0$ & $0.003 *$ & $64.4 \pm 16.9$ & $64.8 \pm 12.8$ & 0.88 \\
\hline Female & $59(42.1 \%)$ & $36(34.0 \%)$ & $0.19^{\dagger}$ & $35(41.7 \%)$ & $29(34.5 \%)$ & $0.24^{\dagger}$ \\
\hline Diabetes & $53(37.9 \%)$ & $48(45.3 \%)$ & $0.24^{+}$ & $31(36.9 \%)$ & $35(41.7 \%)$ & $0.53^{\dagger}$ \\
\hline Insulin treatment & $23(16.4 \%)$ & $17(16.0 \%)$ & $0.93^{\dagger}$ & $12(14.3 \%)$ & $9(10.7 \%)$ & $0.48^{+}$ \\
\hline Obesity $(\mathrm{BMI}>30$ kg/m²) & $40(28.6 \%)$ & $34(32.1 \%)$ & $0.55^{\dagger}$ & $26(31.0 \%)$ & $27(32.1 \%)$ & $0.87^{\dagger}$ \\
\hline Hypertension & $79(56.4 \%)$ & $64(60.4 \%)$ & $0.53^{+}$ & $47(56.0 \%)$ & $47(56.0 \%)$ & $1^{\dagger}$ \\
\hline Smoker (active or past) & $29(20.7 \%)$ & $33(31.1 \%)$ & $0.06^{\dagger}$ & $21(25.0 \%)$ & $23(27.4 \%)$ & $0.73^{+}$ \\
\hline $\begin{array}{l}\text { History of COPD, asthma, } \\
\text { emphysema, fibrosis }\end{array}$ & $22(15.7 \%)$ & $17(16.0 \%)$ & $0.369^{\dagger}$ & $12(14.3 \%)$ & $15(17.9 \%)$ & $0.53^{+}$ \\
\hline eGFR $<60 \mathrm{~mL} / \mathrm{min} / 1.73 \mathrm{~m}^{2}$ & $24(17.1 \%)$ & $17(16.0 \%)$ & $0.82^{+}$ & $13(15.5 \%)$ & $12(14.3 \%)$ & $0.83^{\dagger}$ \\
\hline Solid organ transplantation & $3(2.1 \%)$ & $0(0.0 \%)$ & $0.26 \ddagger$ & $2(2.4 \%)$ & $0(0.0 \%)$ & $0.5 \ddagger$ \\
\hline HIV & $1(0.7 \%)$ & $1(0.9 \%)$ & $1 \ddagger$ & $1(1.2 \%)$ & $0(0.0 \%)$ & $1 \ddagger$ \\
\hline Immunosuppressant drugs & $12(8.6 \%)$ & $5(4.7 \%)$ & $0.24 \ddagger$ & $4(4.8 \%)$ & $4(4.8 \%)$ & $1 \ddagger$ \\
\hline
\end{tabular}


Table 1. Cont.

\begin{tabular}{|c|c|c|c|c|c|c|}
\hline & $\begin{array}{l}\text { Control } \\
\text { Group } \\
(\mathrm{n}=140)\end{array}$ & $\begin{array}{l}\text { Tocilizumab } \\
\text { Group } \\
(\mathrm{n}=106)\end{array}$ & $p$-Value & $\begin{array}{l}\text { Matched } \\
\text { Control } \\
(\mathrm{n}=84)\end{array}$ & $\begin{array}{c}\text { Matched } \\
\text { Tocilizumab } \\
\text { Group }(n=84)\end{array}$ & $p$-Value \\
\hline \multicolumn{7}{|c|}{ Treatments after Admission } \\
\hline No.(\%) under antibiotics & $134(95.7 \%)$ & $106(100.0 \%)$ & $0.04 \ddagger$ & $84(100.0 \%)$ & $84(100.0 \%)$ & NA \\
\hline Betalactamin & $129(92.1 \%)$ & $105(99.1 \%)$ & $0.13^{\ddagger}$ & $81(96.4 \%)$ & $83(98.8 \%)$ & $0.62 \ddagger$ \\
\hline Macrolide & $98(70.0 \%)$ & $93(87.7 \%)$ & $0.001^{+}$ & $64(76.2 \%)$ & $75(89.3 \%)$ & $0.025^{+}$ \\
\hline Others & $21(15.0 \%)$ & $7(6.6 \%)$ & $0.04^{+}$ & $15(17.9 \%)$ & $6(7.1 \%)$ & $0.036^{+}$ \\
\hline No.(\%) under antiviral therapy & $106(75.7 \%)$ & $88(83.0 \%)$ & $0.16^{+}$ & $68(81.0 \%)$ & $68(81.0 \%)$ & $1 \ddagger$ \\
\hline Hydroxychloroquine & $100(71.4 \%)$ & $88(83.0 \%)$ & $0.034^{+}$ & $62(73.8 \%)$ & $68(81.0 \%)$ & $0.27^{+}$ \\
\hline Lopinavir/ritonavir & $8(5.7 \%)$ & $1(0.9 \%)$ & $0.08^{\ddagger}$ & $8(9.5 \%)$ & $1(1.2 \%)$ & $0.03 \ddagger$ \\
\hline $\begin{array}{l}\text { Immunosuppressants and/or } \\
\text { corticosteroids }\end{array}$ & $47(33.6 \%)$ & $43(40.6 \%)$ & $0.26^{+}$ & $24(28.6 \%)$ & $26(31.0 \%)$ & $0.74^{+}$ \\
\hline Baricitinib & $18(12.9 \%)$ & $1(0.9 \%)$ & $0.001 \ddagger$ & $0(0.0 \%)$ & $1(1.2 \%)$ & $1^{\ddagger}$ \\
\hline \multicolumn{7}{|c|}{ Characteristics at Hospital Admission } \\
\hline $\begin{array}{l}\text { Delay between first symptoms and } \\
\text { admission, means } \pm \text { SD, days }\end{array}$ & $5.4 \pm 8.8$ & $4.8 \pm 15.3$ & $0.74^{*}$ & $5.2 \pm 9.8$ & $6.5 \pm 4.9$ & $0.29^{*}$ \\
\hline $\mathrm{SpO}_{2} / \mathrm{FiO}_{2}$ ratio, mean $\pm \mathrm{SD}$ & $327.4 \pm 108.7$ & $338.4 \pm 88.6$ & 0.39 * & $330.3 \pm 108.6$ & $341.8 \pm 87.1$ & $0.45^{*}$ \\
\hline $\mathrm{SpO}_{2}$, mean $\pm \mathrm{SD}, \%$ & $93.9 \pm 3.6$ & $94.0 \pm 3.9$ & $0.81 *$ & $94.0 \pm 3.6$ & $94.2 \pm 3.3$ & $0.62 \S$ \\
\hline Oxygen flow, mean $\pm \mathrm{SD}, \mathrm{L} / \mathrm{min}$ & $4.0 \pm 4.8$ & $3.1 \pm 3.6$ & $0.44 \S$ & $3.9 \pm 4.6$ & $3.0 \pm 3.3$ & $0.54 \S$ \\
\hline $\mathrm{PaO}_{2}$, mean $\pm \mathrm{SD}, \mathrm{mmHg}$ & $70.4 \pm 24.7$ & $68.6 \pm 17.5$ & 0.54 * & $71.6 \pm 28.4$ & $68.6 \pm 17.8$ & $0.46^{*}$ \\
\hline Temperature, mean $\pm \mathrm{SD},{ }^{\circ} \mathrm{C}$ & $37.2 \pm 1.1$ & $37.5 \pm 1.2$ & $0.06^{*}$ & $37.3 \pm 1.1$ & $37.5 \pm 1.2$ & $0.22 *$ \\
\hline C-reactive protein, mean $\pm \mathrm{SD}, \mathrm{mg} / \mathrm{L}$ & $132.1 \pm 99.2$ & $135.2 \pm 88.2$ & 0.79 * & $138.2 \pm 101.7$ & $131.5 \pm 84.6$ & $0.64 *$ \\
\hline Lymphocyte count, mean \pm SD, mcL & $1451.9 \pm 3320.1$ & $1198.6 \pm 1095.7$ & $0.40^{*}$ & $1595.9 \pm 4290.1$ & $1228,7 \pm 1204.0$ & $0.46^{*}$ \\
\hline \multicolumn{7}{|c|}{ Characteristics at Study Inclusion } \\
\hline $\begin{array}{l}\text { Delay between first symptoms and } \\
\text { inclusion, mean } \pm \text { SD, days }\end{array}$ & $8.4 \pm 4.7$ & $8.3 \pm 4.2$ & $0.82 *$ & $8.4 \pm 4,8$ & $8.6 \pm 4.2$ & $0.84^{*}$ \\
\hline $\begin{array}{l}\text { Delay between admission and } \\
\text { inclusion, mean } \pm \text { SD, days }\end{array}$ & $3.0 \pm 8.0$ & $3.5 \pm 14.6$ & $0.28 \S$ & $3.2 \pm 8.5$ & $2,2 \pm 3.3$ & $0.61 \S$ \\
\hline $\mathrm{SpO}_{2} / \mathrm{FiO}_{2}$ ratio, mean $\pm \mathrm{SD}$ & $212.9 \pm 41.7$ & $199.4 \pm 49.8$ & $0.02 *$ & $210.9 \pm 41.9$ & $206.5 \pm 48.7$ & $0.53 *$ \\
\hline $\mathrm{SpO}_{2}$, mean $\pm \mathrm{SD}, \%$ & $94.5 \pm 3.6$ & $94.0 \pm 3.7$ & $0.32 *$ & $94.3 \pm 4.0$ & $94.2 \pm 3.6$ & $0.84 *$ \\
\hline $\mathrm{O}_{2}$ flow support, mean $\pm \mathrm{SD}, \mathrm{L} / \mathrm{min}$ & $8.4 \pm 3.4$ & $9.9 \pm 5.3$ & $0.03 \S$ & $8.6 \pm 3.4$ & $9,3 \pm 4.8$ & $0.59 \S$ \\
\hline $\mathrm{PaO}_{2}$, mean $\pm \mathrm{SD}, \mathrm{mmHg}$ & $74.3 \pm 25.4$ & $76.8 \pm 24.5$ & $0.51^{*}$ & $75.7 \pm 29.0$ & $78.3 \pm 24.8$ & $0.59^{*}$ \\
\hline $\mathrm{PaCO}_{2}$, mean $\pm \mathrm{SD}, \mathrm{mmHg}$ & $36.0 \pm 9.1$ & $35.9 \pm 7.7$ & $0.93 *$ & $36.3 \pm 9.0$ & $35.6 \pm 7.6$ & $0.63^{*}$ \\
\hline $\begin{array}{c}\text { Systolic blood pressure, mean } \pm \text { SD, } \\
\mathrm{mmHg}\end{array}$ & $130.7 \pm 20.0$ & $131.4 \pm 20.9$ & $0.8^{*}$ & $131.3 \pm 21.2$ & $130.8 \pm 20.3$ & $0.9^{*}$ \\
\hline Temperature, mean $\pm \mathrm{SD},{ }^{\circ} \mathrm{C}$ & $37.3 \pm 1.2$ & $37.3 \pm 1.2$ & $0.61 \S$ & $37.3 \pm 1.3$ & $37.3 \pm 1.1$ & $0.55 \S$ \\
\hline C-reactive protein, mean $\pm \mathrm{SD}, \mathrm{mg} / \mathrm{L}$ & $144.9 \pm 100.7$ & $168.0 \pm 95.0$ & $0.07^{*}$ & $150.8 \pm 105.1$ & $163.7 \pm 97.9$ & $0.42 *$ \\
\hline Lymphocyte count, mean \pm SD, mcL & $1224.0 \pm 2294.0$ & $1128.4 \pm 1010.8$ & $0.66^{\S}$ & $1278.8 \pm 2907.4$ & $1168.8 \pm 1108.5$ & $0.75 \S$ \\
\hline eGFR, mean $\pm \mathrm{SD}, \mathrm{mL} / \mathrm{min} / 1.73 \mathrm{~m}^{2}$ & $72.6 \pm 34.7$ & $152.2 \pm 701.9$ & $0.25 *$ & $75.2 \pm 34.5$ & $171.8 \pm 788.2$ & $0.27^{*}$ \\
\hline $\begin{array}{l}\text { Use of non-invasive ventilation or } \\
\text { high flow oxygenotherapy } \\
\text { after inclusion }\end{array}$ & $5(3.6 \%)$ & $8(7.5 \%)$ & 0.17 & $4(4.8 \%)$ & $4(4.8 \%)$ & 1.0 \\
\hline
\end{tabular}

Data are presented as a number (percentage), unless otherwise noted. Comparison methods were noted: * for Student; ${ }^{\dagger}$ for Chi-2; ${ }^{\ddagger}$ for Fischer and ${ }^{\S}$ for Mann-Whitney test. Significant intergroup differences are in bold. Abbreviations: SD: Standard deviation; $\mathrm{O}_{2}$ : oxygen; ACEI: angiotensin conversion enzyme inhibitor; ARB: angiotensin II receptor blocker; BMI: body-mass index; eGFR: estimated glomerular filtration rate by modification of diet in renal disease (MDRD) formula; $\mathrm{FiO}_{2}$ : fraction of inspired oxygen; $\mathrm{HIV}$ : human immunodeficiency virus; IQR: interquartile range; $\mathrm{SpO}_{2}$ : pulse oximetry $\mathrm{O}_{2}$ saturation. Inclusion is defined as when patients present severity criteria for COVID-19 pneumonia, as defined in the Methods section.

\subsection{Propensity-Score Matched Cohort}

Propensity-score matching yielded 84 pairs of patients (for a total of 168 patients in the matched cohort). There was no significant difference between the two matched groups regarding baseline characteristics (see Table 1). In the matched cohort $(n=168)$, treatment with tocilizumab was associated 
with fewer events (hazard ratio $(\mathrm{HR})=0.49(95 \%$ confidence interval $(95 \% \mathrm{CI})=0.30-0.81), p=0.005)$ (see Figure 1).

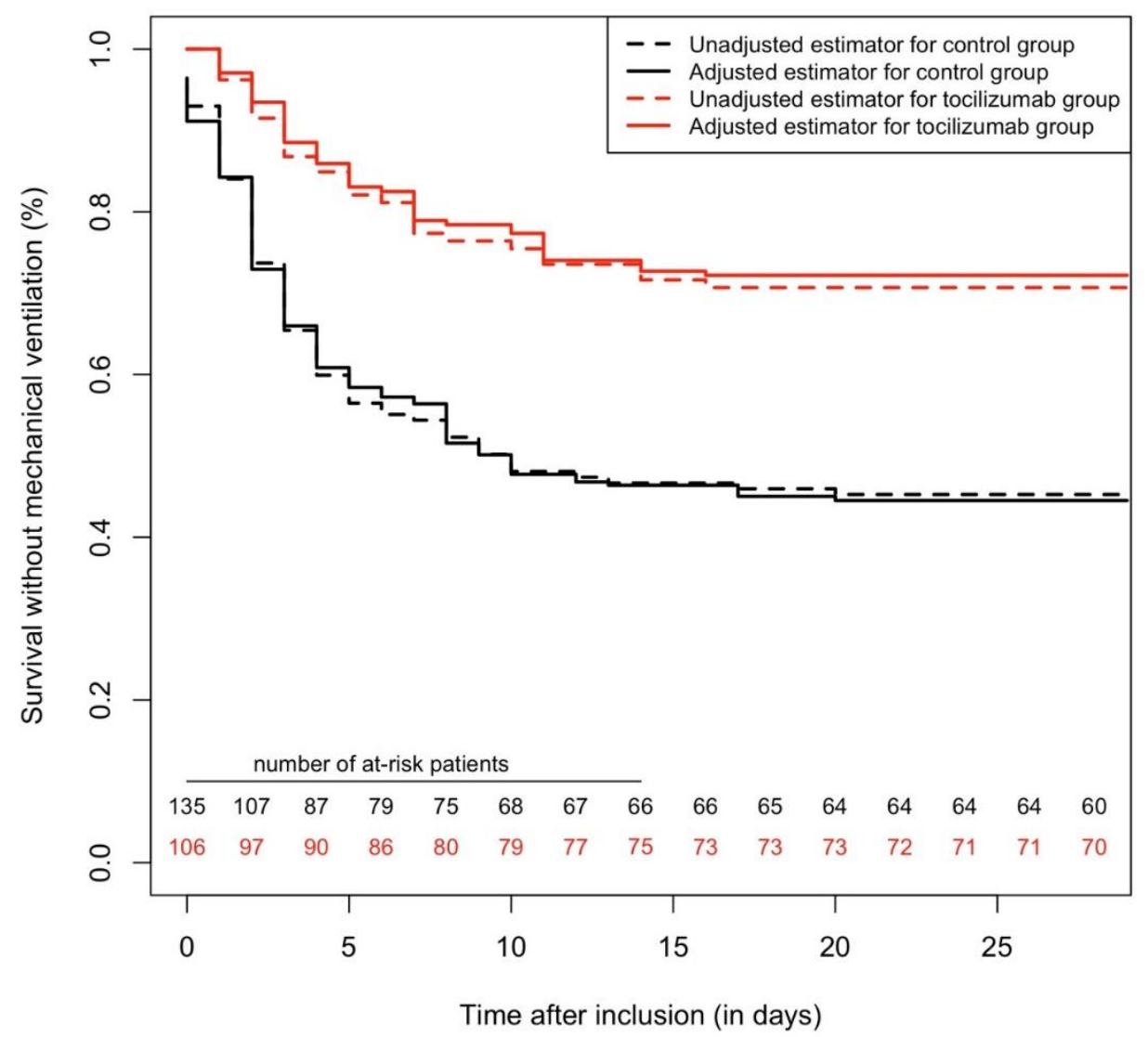

Figure 1. Survival curves, regarding the primary outcome with a 28-day follow-up, comparing tocilizumab and a control group. In the matched cohort $(n=168)$, tocilizumab was associated with fewer events (hazard ratio $(\mathrm{HR})=0.49(95 \%$ confidence interval $(95 \% \mathrm{CI})=0.30-0.81), p=0.005)$. In the overall cohort ( $n=246$ ), Cox multivariable survival analysis found tocilizumab to be independently associated with a lower incidence of the primary outcome (adjusted HR $=0.34(95 \% \mathrm{CI}=0.22-0.52)$, $p<0.0001)$. Inverse probability score-weighted analysis yielded similar results $(p<0.0001)$.

\subsection{Overall Cohort (Cox Multivariable and IPSW Analyses)}

In the overall cohort $(n=246)$, patients in the tocilizumab group were younger than those in the control group $(64.3 \pm 13.0$ vs. $70.1 \pm 16.5$ year-old, $p<0.001)$, more patients under tocilizumab were labeled as having a full engagement status $(73(68.9 \%)$ vs. $71(51.4 \%), p=0.006)$, more were treated with antibiotics $(106(100 \%)$ vs. $134(95.7 \%), p=0.04)$ and by corticosteroids $(43(40.6 \%)$ vs. $38(27.1 \%)$, $p=0.27$ ) (see Table 1 for details on overall cohort). In the tocilizumab group, delay between study inclusion and tocilizumab administration was $1.0 \pm 1.0$ day.

Cox multivariable survival analysis found tocilizumab to be independently associated with a lower incidence of the primary outcome (adjusted HR (adj.HR) $=0.34(95 \% \mathrm{CI}=0.22-0.52), p<0.0001)$. Other variables associated with the primary outcome were: $\mathrm{SpO}_{2} / \mathrm{FiO}_{2}$ ratio on the day of inclusion (per 1 unit increase, adj.HR $=0.987(95 \% \mathrm{CI}=0.983-0.991), p<0.0001)$ and chronic kidney disease (adj.HR $=1.63(95 \% \mathrm{CI}=1.03-2.52), p=0.035)$. IPSW confirmed the protective association between tocilizumab and the primary outcome $(p<0.0001)$ (see Figure 1 ). 


\subsection{All-Cause Mortality (28 Days Maximum Follow-Up)}

When considering all-cause mortality with a maximum follow-up of 28 days, in the matched cohort $(\mathrm{n}=168)$, tocilizumab was associated with fewer deaths $(\mathrm{HR}=0.42(95 \% \mathrm{CI}=0.22-0.82), p=0.008)$. In the overall cohort $(n=246)$, Cox multivariable analysis yielded an independent protective association between tocilizumab and mortality (adj.HR $=0.29(95 \% \mathrm{CI}=0.17-0.53), p<0.0001)$, the other independent variables associated with mortality were full engagement status (adj.HR $=0.11(95 \% \mathrm{CI}=0.05-0.23)$, $p<0.0001), \mathrm{S} / \mathrm{F}$ ratio at inclusion (per 1-unit increase, adj. $\mathrm{HR}=0.99(95 \% \mathrm{CI}=0.985-0.995), p<0.0001)$, chronic kidney disease (adj.HR $=2.0(95 \% \mathrm{CI}=1.22-3.27), p=0.006)$ and systolic blood pressure at inclusion (per 1-mmHg increase, adj.HR $=1.016(95 \% \mathrm{CI}=1.005-1.028), p=0.006)$. IPSW analysis was concordant $(p<0.0001)$ (see Figure 2).

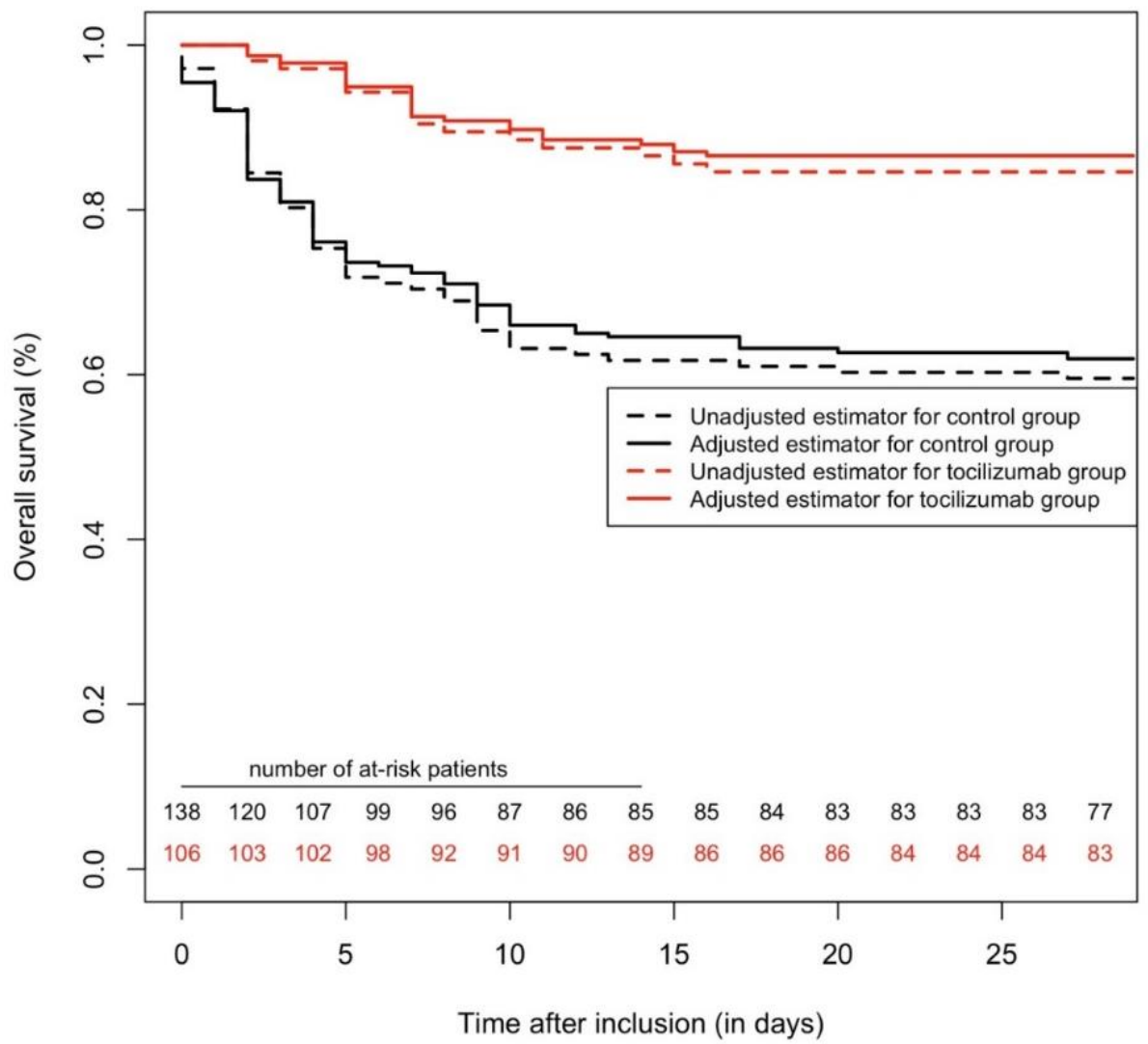

Figure 2. Survival curves, regarding mortality with a 28-day follow-up, comparing tocilizumab and a control group. In the matched cohort $(\mathrm{n}=168)$, tocilizumab was associated with fewer deaths (hazard ratio $=0.42(95 \% C I=0.22-0.82), p=0.008)$. In the overall cohort $(n=246)$, Cox multivariable analysis yielded an independent protective association between tocilizumab and mortality (adjusted $\mathrm{HR}=0.29$ $(95 \% \mathrm{CI}=0.17-0.53), p<0.0001)$. Inverse probability score-weighted analysis yielded similar results $(p<0.0001)$.

\subsection{Sensitivity Analyses}

As the first sensitivity analysis, we focused on the subgroup of patients with a full engagement status. To do so, we excluded all patients labelled as "not to be admitted in ICU" or "not to be mechanically ventilated". This analysis retained 145 patients, including 73 (50.3\%) treated with tocilizumab. In these 145 patients, 43 patients presented the primary outcome. Cox multivariable analyses yielded a protective association between tocilizumab and the primary outcome (adj. $\mathrm{HR}=0.43$ $(95 \% \mathrm{CI}=0.22-0.81) p=0.01)$; the other variables independently associated with the primary outcome were the $\mathrm{SpO}_{2} / \mathrm{FiO}_{2}$ ratio at inclusion (per 1-unit increase, adj.HR $=0.985(95 \% \mathrm{CI}=0.979-0.992)$ $p<0.0001)$ and the temperature at inclusion (per $1{ }^{\circ} \mathrm{C}$-increase, adj.HR $=1.39(95 \% \mathrm{CI}=1.088-1.771)$, 
$p=0.008)$. Similar to the primary outcome, focusing on mortality only, in these 145 patients, 9 died during the 28-day follow-up. Cox multivariable analyses also yielded a protective association between tocilizumab and the mortality (adj.HR $=0.11(95 \% \mathrm{CI}=0.01-0.89) p=0.039)$.

In a second sensitivity analysis, we excluded patients who presented an outcome during the first $48 \mathrm{~h}$, to mitigate other selection bias (including immortal time bias). This dataset comprised 204 patients, with 97 treated by tocilizumab; 63 patients presented the primary outcome, and 46 died during the 28-day follow-up. Using a triple statistical method as in the main analysis, tocilizumab was found to be significantly associated with fewer primary outcomes (Cox multivariable analysis yielded adj.HR $=0.40(95 \% \mathrm{CI}=0.23-0.70), p=0.001)$ (see Figure 3$)$. Similarly, tocilizumab was found to be protectively associated with mortality (adj.HR $=0.36(95 \% \mathrm{CI}=0.18-0.70) p=0.003)$ (see Figure 4) (details of the multivariable models are presented in Supplementary Materials).

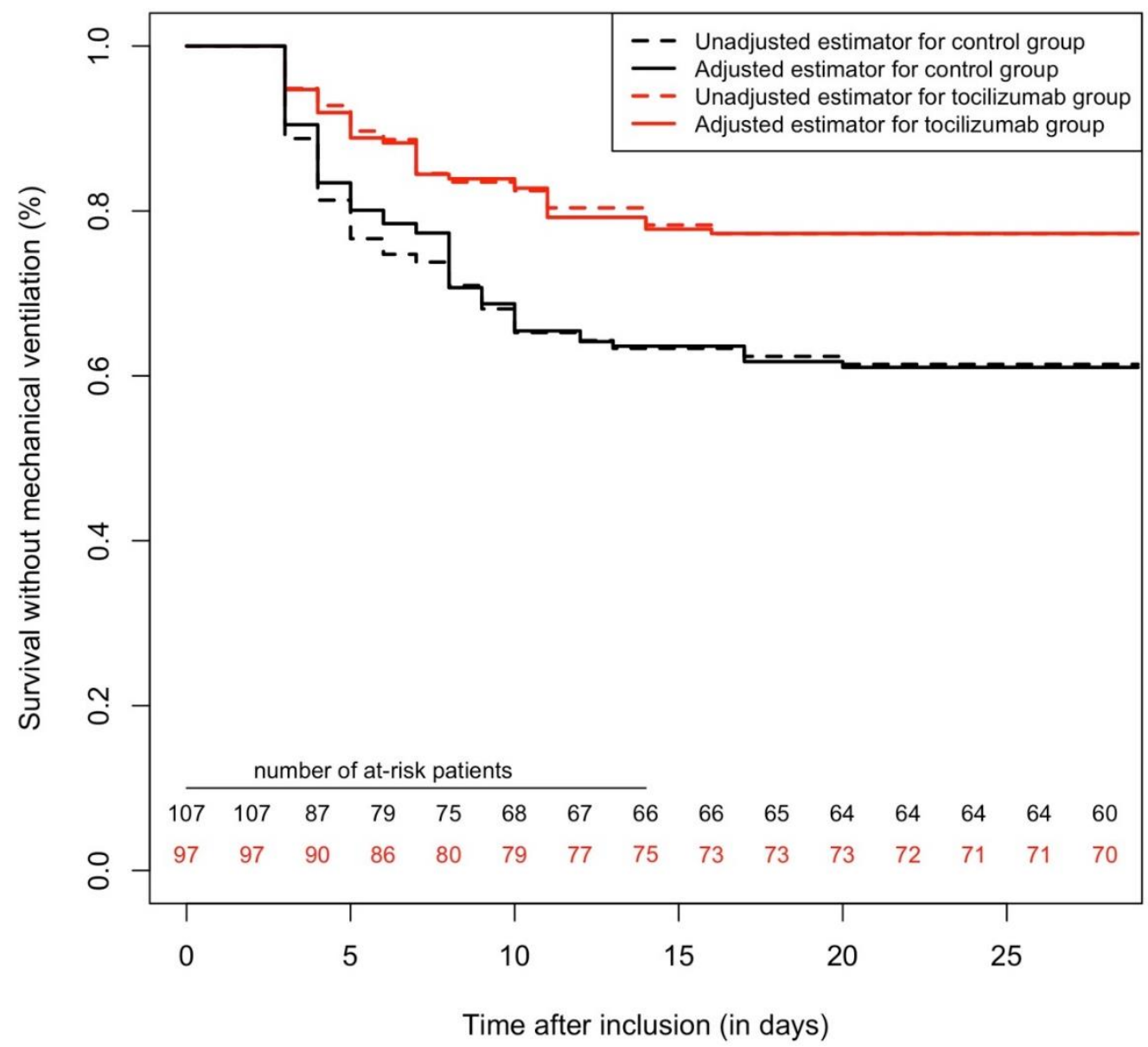

Figure 3. Survival curves, regarding the primary outcome with a 28-day follow-up, comparing tocilizumab and a control group, after excluding patients who presented outcomes in the first $48 \mathrm{~h}$ after inclusion. Cox multivariable analysis yielded a protective association between tocilizumab and the primary outcome (adj.HR $=0.40(95 \% \mathrm{CI}=0.23-0.70), p=0.001)$. 


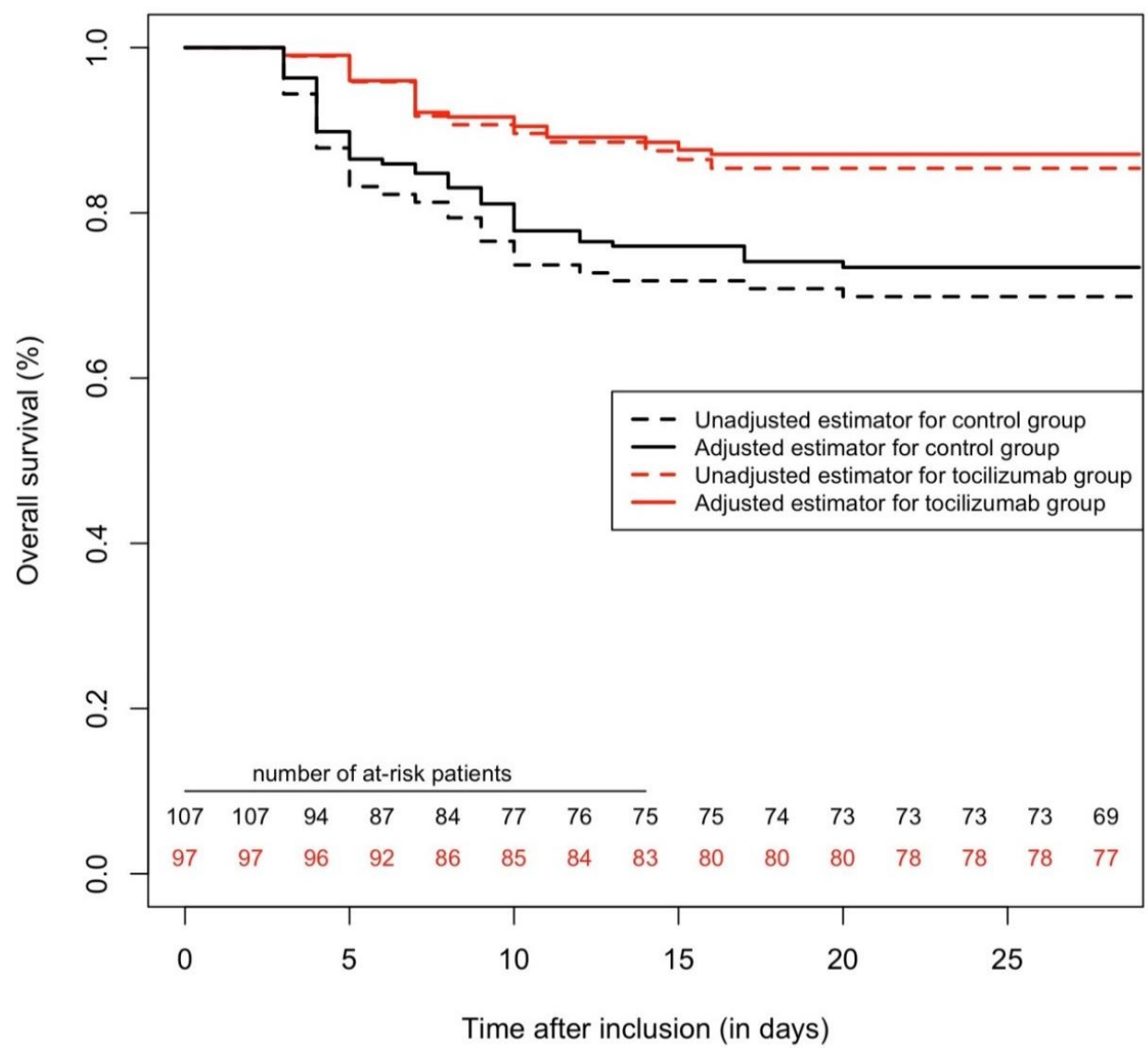

Figure 4. Survival curves, regarding mortality with a 28-day follow-up, comparing tocilizumab and the control group, after excluding patients who presented outcomes in the first $48 \mathrm{~h}$ after inclusion. Treatment by tocilizumab was found to be protectively associated with mortality (adj.HR $=0.36$ $(95 \% \mathrm{CI}=0.18-0.70) p=0.003)$.

\section{Discussion}

As the main finding of this single-center retrospective study, which focused on 246 patients hospitalized for severe COVID-19 pneumonia, we observed a protective association between treatment by tocilizumab and clinical outcomes, which included deaths and invasive mechanical ventilation, at 28-days of follow-up.

The study cohort was similar to that of previously described COVID-19 patients with a median age of 68 years; $27.6 \%$ presented cardiovascular history and $30.1 \%$ were obese [7]. Median delay between first symptoms and treatment was 8 days, corresponding to the delay of CRS onset described in SARS-Cov-2 [8].

Attenuating CRS may partly explain the significant decrease in the primary outcome $[5,6]$. Several therapeutic interventions (corticosteroids, interleukin-1 blockade) have been used to mitigate inflammatory organ injury in viral pneumonia [9]. The recent preliminary results from the RECOVERY trial provides evidence that treatment with dexamethasone reduces mortality in patients with COVID-19 under respiratory support. This study demonstrates the clinical relevance of the strategy based on inflammatory regulation in severe COVID-19 pneumonia [10].

Indeed, CRS was related to interleukin accumulation, and a recent randomized trial studying dexamethasone yielded significant benefits [11], comforting the role of immunomodulation therapeutic strategies [9]. In our study, clinical improvement observed in patients treated by tocilizumab was akin to that described in two observational studies [12,13], the most recent describing 544 patients with severe COVID-19 pneumonia criteria, the beneficial effect of tocilizumab ( $\mathrm{n}=179$ in this group), with an adj.HR of $0.61(95 \% \mathrm{CI}=0.40-0.92)$, regarding the same endpoint as in our study [13]. In these 
two studies, similar to currently enrolling randomized controlled trials, tocilizumab dosage was higher: $8 \mathrm{mg} / \mathrm{kg}$ (up to $800 \mathrm{mg}$ ) in one to three injections. In comparison, in our study, dosage of tocilizumab was $400 \mathrm{mg}$, injected once. Further confirming our results with the same dosage would improve the availability of this costly biotherapy for which access may become an issue.

The preliminary results of the COVACTA trial, testing the effect of tocilizumab in randomized control trial in a heterogeneous cohort of patients, did not show significance of the primary composite endpoint nor secondary mortality endpoint. However, the proportion of patients under mechanical ventilation or in ICU who were excluded in our observational study, is unknown as of now. Moreover, previous observational study protocols mentioned tocilizumab dosage as high as $800 \mathrm{mg}$ twice [12,13], similar to that of ongoing trials with two injections of up to $800 \mathrm{mg}$ each, within a 3-day period [14,15]. In comparison, in our study, dosage of tocilizumab was $400 \mathrm{mg}$, injected once, following previous reports of improved outcomes of chimeric antigen receptor-T-cell-induced CRS with an $8 \mathrm{mg} / \mathrm{kg}$ dosage [4]. Further confirming our results with the same dosage would improve the availability of this costly biotherapy for which access may become an issue [16].

Indeed, in our hospital, reasons for injecting only one dose of $400 \mathrm{mg}$ tocilizumab was mainly driven by cost issues and difficulties in procuring this treatment. It was only made available through the extensive work of our Pharmacology department, even more so that the time of administration corresponded to the first peak of the pandemic in Europe and France in particular. Previous pharmacokinetic and pharmacodynamic analyses of tocilizumab treatment yielded an equivalence between weekly subcutaneous injections of a lower dosage, as compared to intravenous injections once per month, to treat rheumatoid arthritis [17]. Contrary to this chronic disease, COVID-19 may be assimilated to an acute infection and thus, may not require an anti-IL6 effect as prolonged as in rheumatoid arthritis, which may explain how clinical efficacy was obtained so quickly in the present study.

We acknowledge several limitations. First, the single-center nature of this study requires external validation; however, it guarantees homogeneity in the care of all patients, in our non-ICU departments dedicated to treat COVID-19 patients, i.e., observed differences are more likely to be due to tocilizumab. Second, although we aimed to mitigate selection bias using three statistical methods, including propensity-score matching, Cox multivariable and IPSW analyses, residual confounders are plausible $[18,19]$. Due to comorbidities and the lack of beds in the context of the COVID-19 pandemic, a significant proportion of patients were not labeled as having a full-engagement status; hence options were limited regarding the possibilities of being transferred to a critical care medical department, as well as invasive mechanical ventilation. However, these criteria did not alter indications for tocilizumab, as nearly $33 \%$ were limited at admission. Furthermore, we acknowledge that limitation of care is more granular than a binary categorical variable such as "not-to-be-resuscitated", and involves more grades. In this retrospective study, the status of patients was hard to represent accurately, the number one reason for this being that their status evolved through time. Indeed, patients who were at first not to be ventilated, after the first few days, may have changed to be in full engagement, due to signs of improvement. Similarly, patients who were not labeled as limited when they were admitted to medical wards may have been limited during night shifts by the intensivist on duty based on comorbidities or evolution since admission. Accurately representing these variations in a simple model was not feasible, hence, we opted for the most pragmatic approach we had at our disposal: assessing when patients were flagged as full-engagement, as opposed to others. All analyses were adjusted for this criterion in multivariable models. Furthermore, we performed additional sensitivity analyses to further mitigate selection bias; analyses which yielded similar results with significant association between tocilizumab and better survival without mechanical ventilation, even focusing on patients with full therapeutic engagement $(n=155)$.

Third, because arterial partial pressure of $\mathrm{O}_{2}$ was not available in all patients, we used a $\mathrm{SpO}_{2} / \mathrm{FiO}_{2}$ ratio to assess respiratory dysfunction, a validated marker in acute lung injury [20]. Fourth, use of non-invasive ventilation and high-flow oxygen support changed during the study period, 
following evolving guidelines which advocated against doing so during the first weeks of the pandemic to decrease virus aerosol propagation, and were then made more flexible. The relatively low proportion of patients who benefited from these treatments and the fact that there was no difference between the two groups regarding this criterion decreases the chances of it being a bias, although, residual confounding biases may remain. Fourth, there was a mild difference in age between tocilizumab and control groups. However, age was a variable that was accounted for in all multivariable analyses and also in computing the propensity-score. Thus, we did not observe any interaction between age on the efficacy of treatment by tocilizumab. Finally, we did not systematically assay IL-6, which may have proven valuable to identify patients for whom the effect was greater [6].

These results point towards a clinical benefit of tocilizumab; however, they may not replace a fully-fledged randomized controlled trial, focusing on dosage adjustment and on patients managed early, so that CRS may be adequately attenuated in patients with COVID-19 evolving towards clinical deterioration.

\section{Materials and Methods}

\subsection{Study Population}

In this observational single-center study, in a primary care center regional hospital, all patients were screened for COVID-19 starting on 14 March 2020. Diagnosis required positive testing with reverse transcription polymerase chain reaction (RT-PCR) or chest CT-scan with typical lesions [21]. Inclusion criteria was severe COVID-19 pneumonia. Severity criteria required a pulse oxygen saturation $\left(\mathrm{SpO}_{2}\right) \leq 96 \%$ despite oxygen support $\geq 6 \mathrm{~L} / \mathrm{min}$ with oxygen mask, for more than $6 \mathrm{~h}$. We excluded patients with invasive mechanical ventilation (i.e., intubated) and those in the critical care medicine department.

\subsection{Study Design}

Starting on 23 March 2020, tocilizumab was made available for off-label compassionate use in severe COVID-19 pneumonia in our center. Patients were compared between two groups: those who received tocilizumab (a single intravenous injection, $400 \mathrm{mg}$ ) and those who did not (henceforth called the control group, albeit this was not a randomized controlled trial). This retrospective study was approved by a research ethics committee and was registered on clinicaltrials.gov (NCT04366206).

\subsection{Treatment Intervention}

Tocilizumab was made available for compassionate use by hospital pharmacists on 23 March 2020. The choice and indication of treatment depended on an attending physician, and information was given to all patients prior to being treated. No criteria were retained to exclude patients from treatment and patients who were not labeled as being in a full-engagement status by intensivists or attending physicians were still eligible for tocilizumab treatment.

\subsection{Study Variables}

The primary outcome was a composite of all-cause mortality and invasive mechanical ventilation (i.e., requiring tracheal intubation). The follow-up period was 28 days after inclusion. All data were prospectively collected in electronical medical records, which were then extracted for the purpose of this study. A list of the available data is presented in Supplementary Materials. Follow-up was completed for all patients.

\subsection{Statistical Analyses}

The baseline characteristics of patients treated by tocilizumab were compared to that of the control group. In the primary analysis, 1:1 nearest-neighbor propensity-score matching was performed using the following variables: age; sex; smoking status; history of coronary artery disease; stroke; 
heart failure or peripheral artery disease; hypertension; chronic kidney disease with eGFR less than $60 \mathrm{~mL} / \mathrm{min} / 1.73 \mathrm{~m}^{2}$; cancer; long-term corticosteroid treatment; use of antibiotics, of antivirals, of corticosteroids or of baricitinib after admission; $\mathrm{SpO}_{2} / \mathrm{FiO}_{2}$ ratio at admission; time between admission and inclusion; andSpO $\mathrm{O}_{2} / \mathrm{FiO}_{2}$ ratio and CRP at inclusion [18]. A second analysis using a multivariable Cox proportional hazard analysis was performed in the entire cohort, with the following independent covariables: tocilizumab injection, engagement status, age, systolic blood pressure at inclusion, $\mathrm{SpO}_{2} / \mathrm{FiO}_{2}$ ratio at admission and $\mathrm{SpO}_{2} / \mathrm{FiO}_{2}$ ratio at inclusion. A third analysis using an inverse probability score weighting (IPSW) approach was also performed using the entire cohort [19]. Kaplan-Meier curves were used to compare the two groups in the matched cohort. Cox proportional hazards modeling was used to assess the association between tocilizumab and the primary outcome in the overall cohort. Conclusions were drawn only if the three analyses yielded concordant results. Continuous variables were presented as mean \pm standard deviation and categorical variables as a number (proportion). All analyses were performed using SPSS 25.0 (IBM, Armonk, NY, USA) and R software version 3.6.

\section{Conclusions}

In this observational single-center study, in hospitalized patients presenting with severe COVID-19 pneumonia, a single dose of tocilizumab $400 \mathrm{mg}$ was associated with lower mortality and a lesser need for mechanical ventilation.

Supplementary Materials: Supplementary materials are available online at http://www.mdpi.com/1424-8247/13/ 10/317/s1.

Author Contributions: Conceptualization, B.R. and H.G. (Helene Gros); Methodology, B.R. and L.S.N.; Validation, B.R., L.S.N., H.G. (Helene Gros), A.O.; Formal Analysis, L.S.N.; Investigation, B.R., P.Z., F.B., L.D., L.B., H.G. (Helene Guillot), M.-A.B., P.B.; Data Curation, B.R., L.S.N.; Writing-Original Draft Preparation, B.R. and L.S.N.; Writing-Review and Editing, B.R., L.S.N., Y.A., J.-E.S.; Supervision, B.R., L.S.N., H.G. (Helene Gros) and A.O.; Project administration: B.R., H.G. (Helene Gros). All authors have read and agreed to the published version of the manuscript.

Funding: This research received no external funding.

Conflicts of Interest: The authors declare no conflict of interest.

\section{References}

1. Spiteri, G.; Fielding, J.; Diercke, M.; Campese, C.; Enouf, V.; Gaymard, A.; Bella, A.; Sognamiglio, P.; Sierra Moros, M.J.; Riutort, A.N.; et al. First Cases of Coronavirus Disease 2019 (COVID-19) in the WHO European Region, 24 January to 21 February 2020. Eurosurveillance 2020, 25. [CrossRef] [PubMed]

2. Grasselli, G.; Zangrillo, A.; Zanella, A.; Antonelli, M.; Cabrini, L.; Castelli, A.; Cereda, D.; Coluccello, A.; Foti, G.; Fumagalli, R.; et al. Baseline Characteristics and Outcomes of 1591 Patients Infected With SARS-CoV-2 Admitted to ICUs of the Lombardy Region, Italy. JAMA 2020, 323, 1574. [CrossRef] [PubMed]

3. Mehta, P.; McAuley, D.F.; Brown, M.; Sanchez, E.; Tattersall, R.S.; Manson, J.J. COVID-19: Consider Cytokine Storm Syndromes and Immunosuppression. Lancet 2020, 395, 1033-1034. [CrossRef]

4. Le, R.Q.; Li, L.; Yuan, W.; Shord, S.S.; Nie, L.; Habtemariam, B.A.; Przepiorka, D.; Farrell, A.T.; Pazdur, R. FDA Approval Summary: Tocilizumab for Treatment of Chimeric Antigen Receptor T Cell-Induced Severe or Life-Threatening Cytokine Release Syndrome. Oncologist 2018, 23, 943-947. [CrossRef] [PubMed]

5. Liu, B.; Li, M.; Zhou, Z.; Guan, X.; Xiang, Y. Can We Use Interleukin-6 (IL-6) Blockade for Coronavirus Disease 2019 (COVID-19)-Induced Cytokine Release Syndrome (CRS)? J. Autoimmun. 2020, 111, 102452. [CrossRef] [PubMed]

6. Zhang, C.; Wu, Z.; Li, J.-W.; Zhao, H.; Wang, G.-Q. Cytokine Release Syndrome in Severe COVID-19: Interleukin-6 Receptor Antagonist Tocilizumab May Be the Key to Reduce Mortality. Int. J. Antimicrob. Agents 2020, 55, 105954. [CrossRef] [PubMed]

7. Richardson, S.; Hirsch, J.S.; Narasimhan, M.; Crawford, J.M.; McGinn, T.; Davidson, K.W.; the Northwell COVID-19 Research Consortium; Barnaby, D.P.; Becker, L.B.; Chelico, J.D.; et al. Presenting Characteristics, 
Comorbidities, and Outcomes Among 5700 Patients Hospitalized With COVID-19 in the New York City Area. JAMA 2020, 323, 2052. [CrossRef] [PubMed]

8. Han, Y.; Liu, Y.; Zhou, L.; Chen, E.; Liu, P.; Pan, X.; Lu, Y. Epidemiological Assessment of Imported Coronavirus Disease 2019 (COVID-19) Cases in the Most Affected City Outside of Hubei Province, Wenzhou, China. JAMA Netw. Open 2020, 3, e206785. [CrossRef] [PubMed]

9. Huet, T.; Beaussier, H.; Voisin, O.; Jouveshomme, S.; Dauriat, G.; Lazareth, I.; Sacco, E.; Naccache, J.-M.; Bézie, Y.; Laplanche, S.; et al. Anakinra for Severe Forms of COVID-19: A Cohort Study. Lancet Rheumatol. 2020, 2, e393-e400. [CrossRef]

10. The RECOVERY Collaborative Group. Dexamethasone in Hospitalized Patients with Covid-19—Preliminary Report. N. Engl. J. Med. 2020. [CrossRef]

11. Horby, P.; Lim, W.S.; Emberson, J.; Mafham, M.; Bell, J.; Linsell, L.; Staplin, N.; Brightling, C.; Ustianowski, A.; Elmahi, E.; et al. Effect of Dexamethasone in Hospitalized Patients with COVID-19: Preliminary Report. Infect. Dis. 2020. [CrossRef]

12. Toniati, P.; Piva, S.; Cattalini, M.; Garrafa, E.; Regola, F.; Castelli, F.; Franceschini, F.; Airò, P.; Bazzani, C.; Beindorf, E.-A.; et al. Tocilizumab for the Treatment of Severe COVID-19 Pneumonia with Hyperinflammatory Syndrome and Acute Respiratory Failure: A Single Center Study of 100 Patients in Brescia, Italy. Autoimmun. Rev. 2020, 19, 102568. [CrossRef] [PubMed]

13. Guaraldi, G.; Meschiari, M.; Cozzi-Lepri, A.; Milic, J.; Tonelli, R.; Menozzi, M.; Franceschini, E.; Cuomo, G.; Orlando, G.; Borghi, V.; et al. Tocilizumab in Patients with Severe COVID-19: A Retrospective Cohort Study. Lancet Rheumatol. 2020, 2, e474-e484. [CrossRef]

14. CORIMUNO-19-Tocilizumab Trial-TOCI (CORIMUNO-TOCI). 2020. Available online: https://clinicaltrials. gov/ct2/show/NCT04331808201202317 (accessed on 15 October 2020).

15. A Study to Evaluate the Safety and Efficacy of Tocilizumab in Patients With Severe COVID-19 Pneumonia (COVACTA). 2020. Available online: https://clinicaltrials.gov/ct2/show/NCT04320615 (accessed on 15 October 2020).

16. Chiu, Y.; Ostor, A.J.K.; Hammond, A.; Sokoll, K.; Anderson, M.; Buch, M.; Ehrenstein, M.R.; Gordon, P.; Steer, S.; Bruce, I.N. Access to the next Wave of Biologic Therapies (Abatacept and Tocilizumab) for the Treatment of Rheumatoid Arthritis in England and Wales: Addressing Treatment Outside the Current NICE Guidance. Clin. Rheumatol. 2012, 31, 1005-1012. [CrossRef] [PubMed]

17. Abdallah, H.; Hsu, J.C.; Lu, P.; Fettner, S.; Zhang, X.; Douglass, W.; Bao, M.; Rowell, L.; Burmester, G.R.; Kivitz, A. Pharmacokinetic and Pharmacodynamic Analysis of Subcutaneous Tocilizumab in Patients With Rheumatoid Arthritis From 2 Randomized, Controlled Trials: SUMMACTA and BREVACTA: Pharmacokinetic and Pharmacodynamic Analysis of Subcutaneous. J. Clin. Pharmacol. 2017, 57, 459-468. [CrossRef] [PubMed]

18. Lunceford, J.K.; Davidian, M. Stratification and Weighting via the Propensity Score in Estimation of Causal Treatment Effects: A Comparative Study. Stat. Med. 2004, 23, 2937-2960. [CrossRef] [PubMed]

19. Austin, P.C.; Stuart, E.A. The Performance of Inverse Probability of Treatment Weighting and Full Matching on the Propensity Score in the Presence of Model Misspecification When Estimating the Effect of Treatment on Survival Outcomes. Stat. Methods Med. Res. 2017, 26, 1654-1670. [CrossRef] [PubMed]

20. Bilan, N.; Dastranji, A.; Ghalehgolab Behbahani, A. Comparison of the $\mathrm{Spo}_{2} / \mathrm{Fio}_{2}$ Ratio and the $\mathrm{PaO}_{2} / \mathrm{Fio}_{2}$ Ratio in Patients With Acute Lung Injury or Acute Respiratory Distress Syndrome. J. Cardiovasc. Thorac. Res. 2015, 7, 28-31. [CrossRef] [PubMed]

21. Rubin, G.D.; Ryerson, C.J.; Haramati, L.B.; Sverzellati, N.; Kanne, J.P.; Raoof, S.; Schluger, N.W.; Volpi, A.; Yim, J.-J.; Martin, I.B.K.; et al. The Role of Chest Imaging in Patient Management During the COVID-19 Pandemic. Chest 2020, 158, 106-116. [CrossRef] [PubMed]

Publisher's Note: MDPI stays neutral with regard to jurisdictional claims in published maps and institutional affiliations. 